\title{
Effects of treatments with ozonated water in the vineyard (cv Vermentino) on microbial population and fruit quality parameters
}

\author{
Margherita Modesti ${ }^{1}$, Simone Baccelloni ${ }^{2}$, Stefano Brizzolara ${ }^{1}$, Maria Pia Aleandri ${ }^{2}$, Andrea Bellincontro ${ }^{2}$, Fabio \\ Mencarelli ${ }^{2}$, and Pietro Tonutti ${ }^{1 *}$ \\ ${ }^{1}$ Istituto di Scienze della Vita, Scuola Superiore Sant'Anna, Pisa, Italy \\ ${ }^{2}$ Dipartimento per la Innovazione nei sistemi biologici, agroalimentari e forestali, Università degli studi della Tuscia, Viterbo, \\ Italy
}

\begin{abstract}
Ozone $\left(\mathrm{O}_{3}\right)$ is currently employed in wineries as a sanitizing agent and is used to control microbial growth and infection. This molecule decomposes spontaneously to oxygen upon application and the use of ozonated water can represent an alternative for the control of pathogens in the vineyard. Entire canopies of Vitis vinifera (cv Vermentino) plants have been sprayed throughout the vegetative growth with water saturated with $\mathrm{O}_{3}$ to assess the effects of these treatments in reducing the microorganism population, and to evaluate if and how the oxidative stress, induced in the plant by this strong oxidizing agent, affects fruit development, the activity of the cellular antioxidant system, and the production of aromas by the grape berries at ripening. Ozonated water treatments resulted in a partial control of microorganism population, especially considering fungi. Furthermore, the treatments induced a slight delay in the technological maturity of grapes, a significant increase in antioxidant capacity and changes of aroma profile of the grapes at harvest, with an accumulation of monoterpenes. In general, ozonized water treatments showed promising results and seem to be a feasible protocol to be applied in the vineyard in order to reduce the use of chemicals.
\end{abstract}

\section{Introduction}

The European Community imposed a considerable restriction of the use of pesticides, establishing a regulatory framework for the sustainable use of agrochemicals which is based on integrated pest management. Although the viticulture sector represents only $3.3 \%$ of the total cultivated area in Europe, the use of pesticides for grape and wine production accounts for about $65 \%$ of the total employed chemicals in the agricultural sector [1]. In addition to environmental issues, consumers are increasingly oriented towards the purchase of food and beverage see as "safer", which is pushing the wine sector to reduce the use of chemicals. This search for alternatives protocols, which must be effective but also harmless for the environment and human health, has developed great importance both for vineyards and wineries.

Ozone $\left(\mathrm{O}_{3}\right)$ is a strong oxidative gas, which decomposes spontaneously and is employed in an increasing number of wineries as a sanitizing agent, allowing wine production without using sulfur dioxide to clean the equipment and to properly manage wine production (Purovino ${ }^{\circledR}$ method, PC Engineering, Uggiate Trevano, Italy).
In post-harvest, $\mathrm{O}_{3}$ can be used to decrease microbial growth during storage, extending the shelf-life of different horticultural products [2], also promoting the accumulation of bioactive compounds in fruits and vegetables [3-4]. In wine grapes, post-harvest treatments with ozone gas induce specific changes in the aroma profile inducing the production of $\mathrm{C}_{6}$ compounds [5-6].

$\mathrm{O}_{3}$ is also considered a phytotoxic pollutant and crop plants are known to strongly react to elevated ozone concentrations. On the other hand, much less is known about the effects of $\mathrm{O}_{3}$ treatments on perennial crop plants [7]. At cellular level $\mathrm{O}_{3}$ induces an increase in reactive oxygen species (ROS), causing oxidative stress which, if not balanced by a functional antioxidant system, can seriously damage plant tissues [8]. This effect can be reduced when $\mathrm{O}_{3}$ is solubilized in water before its application.

Ozonated water has already been applied in the food industry. It is used to sanitize water and equipment. In previous studies, the ozonated water was successfully applied to decontaminate lettuce [9], table grapes [10] and strawberries [11].

In the wine industry, ozonated water is already used to sanitize tanks, bottles and for the clean-in place program (Purovino $\left.{ }^{\circledR}\right)$. 
The application of ozonated water in the vineyard and the feasibility of its employment to reduce pathogen incidence, as well as its effect on grape fruit physiology and wine quality, still need to be studied. Since $\mathrm{O}_{3}$ is able to retard the development of fungi and the production of spores, it could substitute (at least in part) the use of pesticides in the field and, at the same time, enhance fruit quality and wine preservation.

The main objective of this study was to investigate the effects of pre-harvest treatments with ozonated water in the vineyard on microbial population and fruit development and quality at harvest.

\section{Materials and methods}

\subsection{Plant material and ozone treatments}

The experiment was conducted in 2017 in the Capitini vineyard located in Montiano (GR), Tuscany, Italy (42 $39^{\prime} 31.7^{\prime \prime N}$ latitude, $11^{\circ} 12^{\prime} 43.2^{\prime \prime} \mathrm{E}$ longitude). The ozone generator (A series, PC Engineering, Uggiate Trevano, Italy) has been set with $\max 20 \mathrm{~g} \mathrm{~h}^{-1}$ with $6 \%$ $\mathrm{w} / \mathrm{w}^{-1}$ of ozone and a flow rate at maximum $150 \mathrm{NL} \mathrm{h}^{-1}$ $(\mathrm{NL}=$ normal litre), and it was connected with the water container and the tractor sprayer pump. Water saturated with $\mathrm{O}_{3}$ was employed for the treatments and sprayed directly on the whole canopies of Vitis vinifera (cv Vermentino) plants, weekly, from April $18^{\text {th }}$ to July $13^{\text {th }}$ (from 10-14 through 71-77 BBCH). Eight rows in total were used: four rows treated with ozonated water (ozone) while the other four were used as control. Ten bunches were randomly collected from each row at commercial harvest, after a total of six ozonated water treatments.

\subsection{Microbial population analysis}

Leaf samples were collected after the second treatment (May $5^{\text {th }}$ ) and washed for 2 hours with phosphate-saline buffer (PBS). Serial dilutions were made and plated on agarized medium. The culture media used are semiselective for the different microbial communities such as fungi, bacteria and yeasts. The bacterial population was isolated on Plate Count Agar (PCA) medium (5g / 1 triptone, $2.5 \mathrm{~g} / 1$ glucose, $1 \mathrm{~g} / 1$ yeast extract, $15 \mathrm{~g} / 1$ agar,100 mg/l Cyclohexamide. The fungal population was isolated on Potato Dextrose Agar (PDA) (Oxoid) with the addition of the antibiotic streptomycin sulphate. Yeasts were isolated on Yeast Extract Peptone Dextrose agar (YEPD) (yeast extract $10 \mathrm{~g} / 1$, peptone $20 \mathrm{~g} / 1$, glucose $20 \mathrm{~g} / 1$, agar $20 \mathrm{~g} / \mathrm{l}$ ). The incubation was carried out at $25{ }^{\circ} \mathrm{C}$ for 5 days. The colonies of the different microorganisms were counted, and the Colony Forming Units (UFC) / g were calculated based on the different serial dilutions previously made.

\subsection{Grape berry parameters}

Thirty berries for each set of bunches (ten sets for each treatment) were used for technological parameters analyses. The juice was extracted from the berries and used for the following analyses: total phenolic content (TPC, Folin-Ciocalteu method [12]) expressed as mg of gallic acid equivalents (GAE) per L; total soluble solids (TSS) using an optical refractometer ( ${ }^{\circ}$ Brix); titratable acidity (TA), titrating the acids present in grape juice with sodium hydroxide $(0.1 \mathrm{~N})$, (expressed as $\%$ tartaric acid). Total antioxidant capacity (TAC) was determined using a commercial kit (Total Antioxidant Capacity Assay Kit, Cat. No. MAK187; Sigma-Aldrich, Italy).

\subsection{HS-SPME-GC-MS}

For the volatile organic compounds (VOCs) analysis, thirty berries were homogenized with $1: 1$ of $\mathrm{NaCl}$ buffer solution (saturated) by using an UltraTurrax (Mod. T25, IKA) and immediately frozen in liquid nitrogen until the analysis. Samples were thawed and $4 \mathrm{~g}$ were weighed in a $20 \mathrm{~mL}$ glass crimped vial for headspace analysis (Cat. No. SU860049, Sigma-Aldrich, Italy) sealed with silicone septa for SPME (Cat. No. 27362, SigmaAldrich, Italy), and incubated for 1 hour at $40{ }^{\circ} \mathrm{C}$. The VOCs were sampled at the same temperature for $45 \mathrm{~min}$ using an SPME fiber $(50 / 30 \mu \mathrm{m}, \mathrm{DVB} / \mathrm{CAR} / \mathrm{PDMS}, 2$ $\mathrm{cm}$ long; Supelco, Bellefonte, PA, USA). The fiber was desorbed into the injector of the GC set at $250{ }^{\circ} \mathrm{C}$ for 5 min (splitless mode). A Clarus 680 Gas Chromatograph equipped with a split/splitless injector (PerkinElmer $\AA$, Waltham, Massachusetts) was used for the analysis. Volatiles were separated on a fused-silica capillary column (DB-Wax, $60 \mathrm{~m}, 0.32 \mathrm{~mm}$ ID, $0.25 \mu \mathrm{m}$ film thickness; Restek, Bellefonte, PA). Helium was used as carrier gas with a flow rate of $1 \mathrm{~mL} \mathrm{~min}^{-1}$. The GC-MS settings employed were the same adopted by Genova and Montanaro [13]. For the identification of the compounds, a mass spectrometer (Clarus 500 Mass spectrometer, PerkinElmer®, Waltham, Massachusetts) coupled to the $\mathrm{GC}$ was used. Each chromatogram was deconvoluted using AMDIS software (National Institute of Standards, Gaithersburg, MD, USA). Each peak was identified by comparing the experimental spectra with those of the National Institute for Standards and Technology (NIST98, Version 2.0, USA) data bank including only compounds with $75 \%$ of identity or more.

\subsection{Statistical analysis}

All the analyses were performed in ten replicates. Partial least squares discriminant analysis (PLS-DA) was performed on the normalized data of the experiment using the JMP software (JMP ${ }^{\circ}$, Version 14 SAS Institute Inc., Cary, NC, 1989-2007) to analyse the GCMS data. The technological parameters and pathogens growth data were compared by unpaired t-test with Welch's correlation $(\mathrm{P}<0.05)$ using Graphpad Prism 7.01 (GraphPad Software, La Jolla, CA, USA). 


\section{Results and discussion}

Ozone treatment showed a reduction effect only on fungi while, unexpectedly, the UFC was higher for bacteria and yeasts (Table 1).

Table 1 Concentration (UFC / g of leaf) of microorganisms on leaves after the second treatment with ozonated water (May 5th, 2017). Data are the mean ( \pm SD) of three replications

\begin{tabular}{|c|c|c|c|}
\hline & Bacteria & Fungi & Yeasts \\
\hline Control & $40.7 \pm 4.3$ & $15.3 \pm 1.7$ & $18 \pm 2.0$ \\
\hline Ozone & $54.7 \pm 2.5$ & $8.0 \pm 2.0$ & $39.3 \pm 1.2$ \\
\hline
\end{tabular}

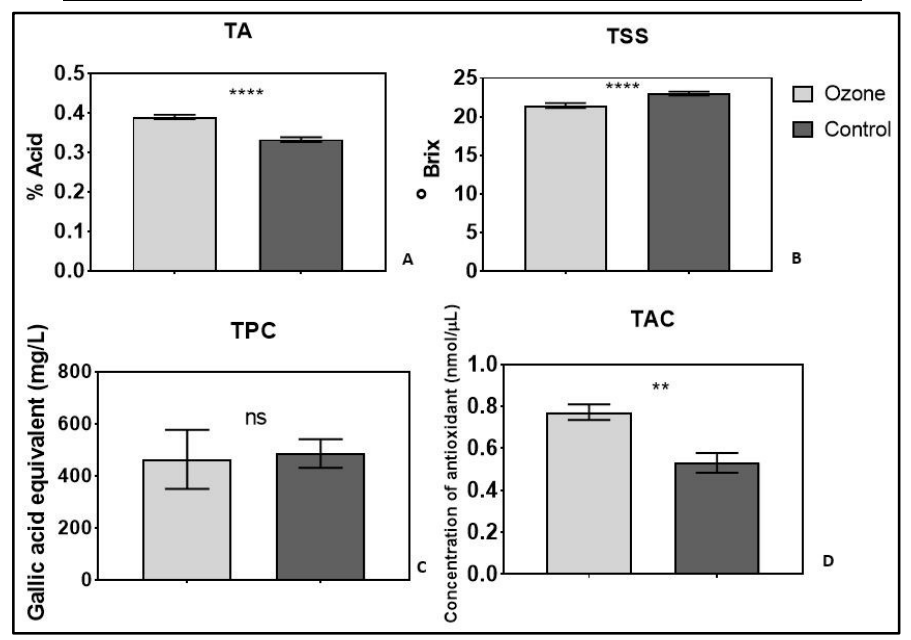

Fig. 1 A. TA (\%); B. TSS ( ${ }^{\circ}$ Brix); C. TPC (Gallic acid equivalent $\mathrm{mg} / \mathrm{l}$ ); D. TAC (Trolox equivalent $\mathrm{nmol} / \mu \mathrm{L}$ ) in berries (cv Vermentino) at commercial harvest after six ozonated water treatments on the whole canopies. Control refers to untreated fruit. Values are the mean $( \pm S D)$ of ten replications. Asterisks indicate a significant difference between the two sample values. $* * * * \mathrm{P}<0.0001 ; * * \mathrm{P}<0.0029$; ns no significant differences

Ozone treatments affected the sugar concentration and TA of the grapes at commercial harvest. In particular, a statistically significant higher level of acidity was observed in treated grapes (Fig. 1A), which also showed a slight but significant lower amount of soluble solids. The decrease of TSS in berries after vine fumigation with $\mathrm{O}_{3}$ has already been reported [7]. These data suggest that ozonated water treatments slightly delay the ripening process. Previous published papers [7, 14] indicate that $\mathrm{O}_{3}$ treatments enhance senescence and reduce photosynthetically active green leaf area with possible effects on carbohydrate synthesis and translocation.

Ozonated water treatments did not significantly affect TPC level (Fig. 1.C). Despite that, ozone increased the TAC of the treated berries (Fig. 1D). This enhanced total antioxidant activity is probably caused by an increase of the antioxidant enzymes activity and/or a specific class of phenolic compound, which is undetectable using the Folin-Ciocalteu method.
$\mathrm{O}_{3}$ is one of the most powerful oxidizing agents, which stimulates the biosynthesis of phenolic compounds in table grapes $[15,16]$. Post-harvest treatment leads to an accumulation of different phenolic fractions [3, 17, 18], and an increase in antioxidant enzymes activity such as CAT, APX, GPX and SOD, in wine grapes [19], papaya [20] and pear [21].

$\mathrm{O}_{3}$ penetrates leaves through the stomata and it is immediately and spontaneously decomposed to ROS, in particular $\mathrm{H}_{2} \mathrm{O}_{2}$ [22]. Plant cells have a system of enzymatic and non-enzymatic antioxidants that are effective in maintaining ROS balance. The activation of the biosynthetic pathway of antioxidant compounds (such as polyphenols) and the increase in antioxidant enzymes activities protect the cells against the oxidative stress.

However, it must be reported that Bortolin et al [23] showed a decrease activity of the antioxidant enzymes in red pepper plants, in response to chronic exposure to high concentration of gaseous $\mathrm{O}_{3}$, suggesting that high concentration of $\mathrm{O}_{3}$ reduces the capacity of the plants to react to the oxidative stress and the toxic effect of ROS.

The effect of ozone is strongly dependent on its concentration and type of application; in our case, the use of ozonated water seems to induce an increase in the antioxidant capacity but not in the TPC. It cannot be ruled out that the ozonated water treatments modulated the synthesis of specific classes of phenolic compounds, such as flavonols and flavanols, as reported in previous studies [3, 17].

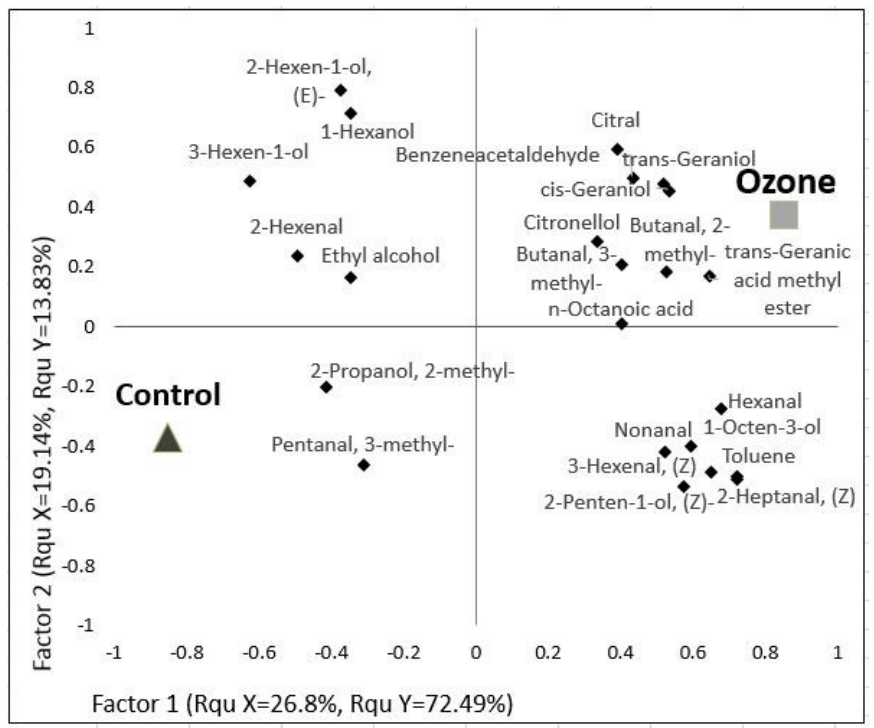

Fig. 2 Partial Least Squares Analysis (PLS): a total of 23 compounds were selected and used as predictor variables, whereas ozone-treated and control grapes were used as response variable

Grape berries aromatic profiles were also analysed at commercial harvest. A total of 48 compounds were identified employing the SPME-GC-MS approach. A PLS model was created to study the differences among treatments. By means of a multivariate analysis, a total of 23 compounds were selected based on their variable importance in projection scores (VIPs) to highlight 
differences between ozone and control grapes, which contributed the most to samples clustering (Fig. 2).

In this model, which explains $86,32 \%$ of the variability, the two treatments are clearly separated and sit in opposite quadrants. Ozone treated grapes are characterized by higher amounts of monoterpenoids compared to control grapes. Ozone treated samples were also characterized by the presence of citral, citronellol, cis and trans geraniol and trans-geranic acid methyl ester.

Vermentino is classified as neutral cultivar, characterized by a slight prevalence of monoterpenes [24]. Here, the increase of these compounds after the treatment could represent a positive change. In fact, terpenes are typically associated with pleasant floral notes [24].

The stimulation of terpene biosynthesis by oxidative stress has already been reported [25, 26] and it is observed that their synthesis is activated in response to stress in general. Loreto et al [25] suggested that monoterpenes are involved in the antioxidant system because they quickly react with ROS, degrading them [27]. Since $\mathrm{O}_{3}$ stimulates the production of ROS, it cannot be excluded that the production of ROS, acting as a signal, leads to the formation of monoterpenes to protect the cells from the oxidative stress. However, the role of monoterpenes in response to stress still needs to be clarified.

\section{Conclusions}

Ozonated water treatments induced a reduction of fungi infection while, unexpectedly, the result was opposite for bacteria and yeasts, which showed higher UFC on treated leaves. A similar experiment was carried out in 2016 (data not shown) when ozonated water was more effective in reducing the microbial population of fungi and yeasts, but not of bacteria (data not shown). The 2016 and 2017 seasons were markedly different in terms of climatic parameters and the different results obtained in the two years suggest that the evaluation of the effects of ozonated water treatments must also take into consideration these environmental factors. In addition, during 2017 the ozone-treated rows were positioned between two untreated rows and this may have had an impact on what was observed in terms of microbiological parameters. Generally speaking, this study demonstrates that ozonated water represents a promising option for a control of microorganisms in the vineyard. Ozonated water treatments leads to the activation of the plant antioxidant system, protecting the cells against the oxidative stress, alter the VOC profile of berries at harvest, and seems to induce a slight delay in berry ripening evolution. If confirmed, this effect, together with the possible protective action against pathogens, may be of great interest for practical application of ozonated water treatments in the vineyards.

\section{References}

1. Eurostat report (2007)
2. A.G. Perez, C. Sanz, J.J. Rios, R. Olias, and J.M. Olias. J. Agric. Food Chem. 47, 16521656 (1999)

3. K. Carbone, and F. Mencarelli. Food Bioprocess Tech., 8, 1739-1749 (2015)

4. N. Tzortzakis, and A. Chrysargyris, Food Reviews Int. 23-51 (2016)

5. F. De Sanctis, B. Ceccantoni, A. Bellincontro, F. Mencarelli, C. D’Onofrio, E. Ducci, and C. Catelli. Acta Hort. 1071, 795-800 (2015)

6. K. Carbone, $\mathrm{PhD}$ thesis, University of Tuscia, Viterbo, Italy (2015)

7. G. Soja, M. Eid, H. Gangl, and H. Redl. Phyton, 37, 265-270 (1997)

8. R. Mittler. Trends in Plant Sc. 7, 405-410 (2002)

9. N.G. Tzortzakis, I. Singleton, J. Barnes. Post. Biol. Technol 43, 261-270 (2007)

10. H. Olmez, and M.Y. Akbas. J Food Eng 90, 487-494 (2009)

11. M. Achen, and A.E. Yousef. J. Food Sci 66, 1380-1384 (2001)

12. V.L. Singleton, and J.A. Rossi J.A. AJEV, 16, 144-158 (1965)

13. G. Genova, and G. Montanaro, Application note, Perkin Elmer (2012)

14. E.J. Pell, C.D. Schlagnhaufer, and R.N. Arteca. Phys Plant 100, 264-273 (1997)

15. R. Gonzalez-Barrio, D. Beltran, E. Cantos, M.I. Gil, J. C. Espin, and F.A. Tomas- Barberan. J Agric Food Chem 54, 4222-4228 (2016)

16. F., Artés-Hernández, E. Aguayo, F. Artés, and F. Tomás-Barberán. J Sc of Food Agr 87, 82483 (2007)

17. F. Mencarelli, B. Ceccantoni, A. Bellincontro, C. Catelli, and D. Di Mambro. Vite,Vino, Qualità 4, 24-27 (2011)

18. A. Bellincontro, C. Catelli, ,R. Cotarella and F. Mencarelli. Aust j grape wine r. 10.111 (2017)

19. M. Modesti, M. Petriccione, R. Forniti, L. Zampella, F. Mastrobuoi, M. Scortichini, and F. Mencarelli. Food Res Int, in press.

20. M.K. Ong, A. Ali, P.G. Alderson, C.F. Forney. Sci Hortic 179, 163-169 (2014)

21. Z. Zhao, G. Xu, Z. Han, Q. Li, Y. Chen, and D. Li. J Food Qual 36, 190-197(2013)

22. A. Castagna, and A. Ranieri. Environ Pollut, 157, 1461-1469 (2009)

23. R.C. Bortolin, F.F. Caregnato, A.M. Divan, F.H. Reginatto, D.P. Gelain, J.C. Fonseca Moreira. Ecotoxicol Environ Saf 100, 114-121 (2014)

24. C. D’Onofrio. Italus Hortus 18, 2: 39-61 (2011)

25. F. Loreto, P. Pinelli, F. Manes, and H. Kollist. Tree physiol 24, 361-367 (2004) 
26. Sharkey and F. Loreto. Oecologia 95, 328-333 (1993)

27. M.S. Waring and J.R. Wells. Atmos Environ 106, 382-391 